\title{
Microstructure and mechanical properties study of slip-cast copper-alumina composites
}

\author{
M. Stratigaki ${ }^{1}$ W. Pabst $^{2}$ - V. Nečina ${ }^{2} \cdot$ M. Hajíček ${ }^{3}$ A. D. Gotsis ${ }^{1}$
}

(c) Springer Nature Switzerland AG 2018

\begin{abstract}
Alumina matrix composites reinforced with metallic copper were produced and their microstructure and mechanical properties were studied. The composites were fabricated by aqueous slip casting technique, and sintered at $1500^{\circ} \mathrm{C}$ in a hydrogen atmosphere. The samples showed low porosity and a core-skin structure with copper-free skin and a uniform spatial distribution of copper particles in the core. The addition of metallic Cu particles at low amounts in the $\mathrm{Al}_{2} \mathrm{O}_{3}$ matrix resulted in a small reduction in the stiffness and the hardness but augmented impact resistance. The mechanical properties of the composites were in good agreement with porosity-corrected predictions of the simple rule of mixtures, indicating that this fabrication method produces composites for which the enhanced toughness is not accompanied by a large reduction of their other mechanical properties.
\end{abstract}

Keywords Aluminum oxide $\cdot$ Composites $\cdot$ Copper $\cdot$ Elastic modulus $\cdot$ Impact $\cdot$ Microstructure

\section{Introduction}

The fabrication of composite materials consisting of a ceramic matrix reinforced with metal particles is a research field that is still drawing a lot of attention $[45,81]$. The drive to develop these ceramic-based composites with augmented mechanical properties stems from the inherent brittleness of ceramics, something that renders them unsuitable for some high-performance applications [10, $26,27,32,67]$. The dispersion of ductile metal particles in the brittle ceramic matrix, however, has been found to enhance the toughness of the material [37].

A number of mechanisms have been proposed to explain how the metallic particles may interact with a propagating crack in ceramic matrices $[8,9,17]$. Due to their ductile nature, the metallic inclusions may deform plastically, bridge the advancing crack and stretch until they fracture or debond, thus, absorbing a significant amount of energy [3]. It is also possible that the particles may cause tilt of the crack via crack deflection $[28,29]$, or branching [30]. Any of these interactions is possible, either acting alone or simultaneously in a synergistic way. In principle, the aim of dispersing the reinforcing particles in the matrix is to create a tortuous path for the crack and, thus, delay its propagation through the material.

Aluminum oxide (alumina) is a widely used engineering ceramic material that has low density, high hardness, high stiffness, thermal and chemical stability and good corrosion resistance $[14,16,46]$. When these properties are combined with the ductility and high thermal conductivity of a metal, composite structures with a promising performance may be expected. The dispersion of metal particles such as: Mo [25, 47], Ni [64, 70, 76], Ag [19], W [61] in alumina has been found to improve the fracture toughness following the mechanisms mentioned above.

$\triangle$ M. Stratigaki, mstratigaki@isc.tuc.gr; W. Pabst, pabstw@vscht.cz; V. Nečina, Vojtech.Necina@vscht.cz; M. Hajíček, hajicek@ujp.cz; A. D. Gotsis, gotsis@science.tuc.gr| 'School of Mineral Resources Engineering, Technical University of Crete, University Campus, Akrotiri, 73100 Chania, Greece. ${ }^{2}$ Department of Glass and Ceramics, University of Chemistry and Technology, Prague (UCT Prague), Technická 5 , 16628 Prague 6, Czech Republic. ${ }^{3}$ UJP PRAHA a.s., Nad Kamínkou 1345, Zbraslav, 15610 Prague, Czech Republic. 
In the present work, $\mathrm{Cu} / \mathrm{Al}_{2} \mathrm{O}_{3}$ composites containing different amounts of metallic copper powder were prepared and studied. Given the high ductility and fracture toughness of copper this combination is likely to have a great potential for mechanical properties improvement [15]. The relevant studies on this system in the literature $[1,49,79]$ have been limited to low copper loading (up to 5 vol\%), while in the present article we report the microstructure and the mechanical response over a wider range of compositions.

Further, the copper/alumina system has scientific interest because the metallic inclusions show a melting point below the usual sintering temperature of the matrix. The latter brings in two potential problems that will affect the properties of the sintered ceramic composite: (a) The high interfacial tension between the metallic melt and the crystalline alumina, i.e. the tendency of molten copper to remain spherical in order to minimise its surface energy, in combination with the difference in their thermal expansion coefficients may lead to poor adhesion and possible voids at the interfaces. (b) Part of the reinforcement may be lost during sintering due to, e.g., flow through the pores and evaporation. The extend of these problems and eventual solutions for the manufacturing of advanced composites of this type are not well documented yet.

Anticipating the two potential problems above, the forming of the green samples was realized by employing the versatile aqueous slip-casting method [50,53, 82] and very fine alumina powder. The major advantage of this method is the better initial particle packing of the green parts compared to conventional dry-pressing processing routes [6]. This leads to lower porosity in the green parts and can somewhat alleviate the problems mentioned above, so that hot pressing is not required for efficient sintering.

In the present study the microstructure of the fabricated copper/alumina samples was evaluated and analysed. The elastic modulus, the impact strength, and the Vickers microhardness of the sintered specimens were determined, and the results are discussed.

\section{Experimental procedure}

\subsection{Fabrication}

Commercially available a-alumina powder (Almatis CT3000SG) and copper powder (Sandvik Osprey Ltd.) were selected as the raw materials. Figure 1 depicts the volume-weighted particle size distributions of the raw powder materials determined with the laser particle sizer Analysette 22 Nanotec (Fritsch $\mathrm{GmbH}$ ). The $\mathrm{D}_{50}$ (median size) values were $0.7 \mu \mathrm{m}$ and $17 \mu \mathrm{m}$ for alumina and copper powders, respectively. The slip casting technique was used to prepare the samples. The $\mathrm{Al}_{2} \mathrm{O}_{3}$ and $\mathrm{Cu}$ powders were mixed in the required proportions in distilled water to form a series of aqueous suspensions containing 40-43 vol\% total solids content. A water-miscible alkali-free, purely organic deflocculant (Dolapix CE64, Zschimmer \& Schwarz, Germany) was used to prevent particle agglomeration and to stabilise the suspensions. The optimum deflocculant concentration was approx. $0.5 \%$ of the solids content in all cases.

The slurries were homogenised in a laboratory flat horizontal shaker (HS 260 Basic, IKA) using polyethylene bottles for $90 \mathrm{~min}$ and alumina spheres. Then, they were
Fig. 1 Volume-weighted particle size distributions (symbols for cumulative volume; lines for relative volume) of the alumina powder and the copper powder measured by laser diffraction

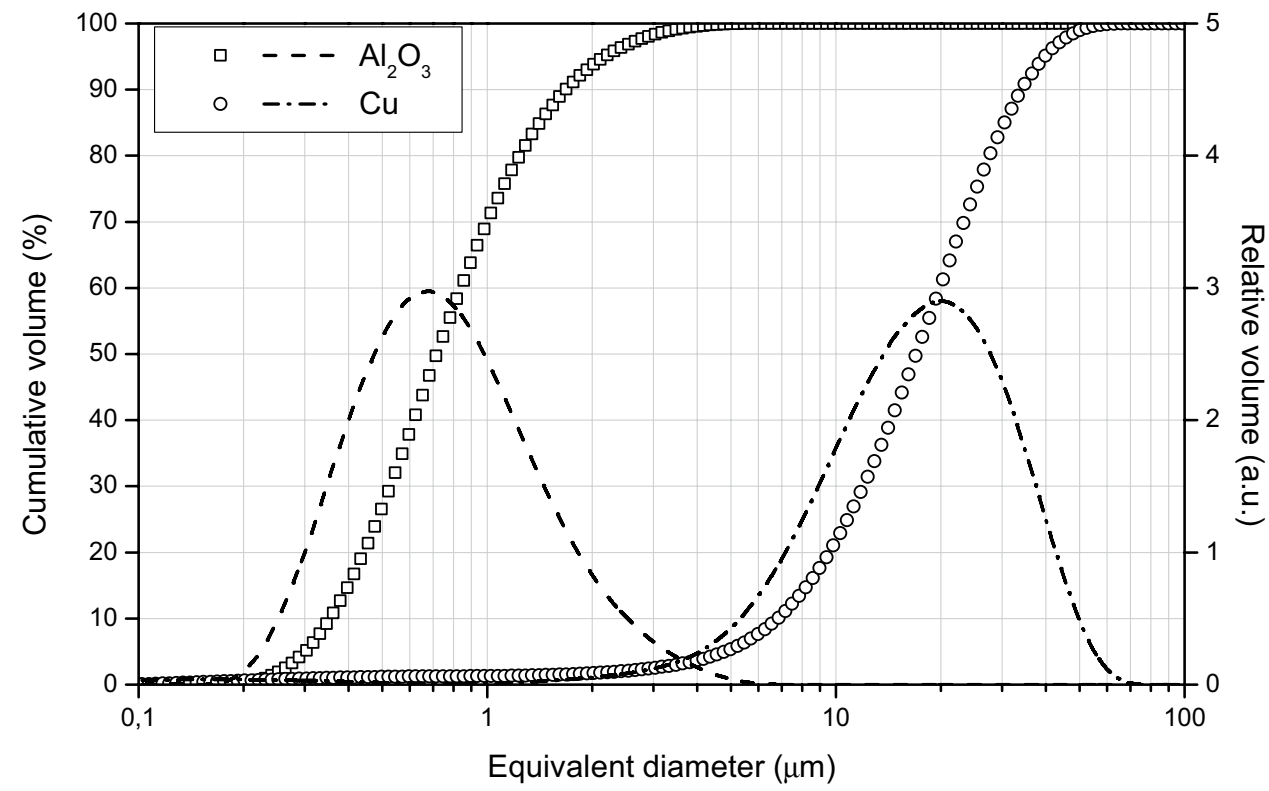


ultra-sonicated (UP200S, Hielscher Ultrasonics) and cast into Plaster-of-Paris moulds to fabricate rod-shaped cylindrical samples with dimensions of around $5 \mathrm{~mm}$ in diameter and $50 \mathrm{~mm}$ in length. The parts were allowed to dry in the moulds for a short period of time. After demoulding and drying in air at room temperature for $24 \mathrm{~h}$, the samples were further dried stepwise at $40,60,80$ and $110^{\circ} \mathrm{C}$.

The sintering of the green samples was performed in an oven, without exerting pressure, under a reducing (hydrogen) atmosphere to prevent the oxidation of the metal phase. The temperature profile included a gradual increase up to $600^{\circ} \mathrm{C}$ at a heating rate of $1^{\circ} \mathrm{C} / \mathrm{min}$, and $2 \mathrm{~h}$ dwell time at this temperature to ensure the burn-out of the organic binder. Finally, the temperature increased to $1500^{\circ} \mathrm{C}$ at a heating rate of $2^{\circ} \mathrm{C} / \mathrm{min}$ and the sintering of the parts was performed at this temperature for $2 \mathrm{~h}$ under a pure hydrogen flow of about $3 \mathrm{~L} \mathrm{~min}{ }^{-1}$.

\subsection{Characterization}

The density of the green samples was estimated directly by weighing their mass, and measuring their diameter and length with a caliper. The sintered samples were characterized in terms of bulk density and open porosity using Archimedes' immersion technique, i.e. the hydrostatic (buoyancy) method according to standard [21], after $1 \mathrm{~h}$ evacuation and immersion in water for soaking time of $24 \mathrm{~h}$. The relative density is the ratio of the measured density over its theoretical density, $\rho$, calculated for each composition using the rule of mixtures:

$\rho=V_{f} \rho_{\mathrm{Cu}}+\left(1-V_{f}\right) \rho_{\mathrm{Al}_{2} \mathrm{O}_{3}}{ }^{\prime}$

where $V_{i}$ and $\rho_{i}$ denote the volume fraction and the theoretical density of the constituent phases $\left(3.987 \mathrm{~g} \mathrm{~cm}^{-3}\right.$ for alumina and $8.941 \mathrm{~g} \mathrm{~cm}^{-3}$ for copper [15]), and the subscript $f$ stands for the filler.

The crystalline phases of the composites were identified by X-ray diffraction analysis (D8 Advance Bruker AXS) with a $\mathrm{Cu}$ anode and a detector with a LynxEye Ni filter. The scanning angle was between 4 and $80^{\circ}$, the recording step was $0.02^{\circ}$, and the time step was $0.2 \mathrm{~s}$. The preparation required crushing the sample and milling it to fine powder manually in an agate mortar. The rod-shaped sintered samples were sectioned and mounted into a resin medium. After the complete curing of the resin, the crosssectional surfaces were grind and polished with diamond paste to produce a smooth finish using a Struers Planopol V Grinder/Polisher machine and water as a cooling media. The microstructures were observed by optical microscopy and analysed using an open source image processing program (ImageJ: [63]). The fracture surfaces of the samples were sputtered with graphite to prevent charging and were examined using scanning electron microscopy (JEOL
JSM 5400). EDS was used to identify the components on the SEM surfaces.

\subsection{Mechanical properties}

The elastic behaviour (Young's modulus) of the samples was determined by Impulse Excitation (IET) measurements at room temperature [4]. IET is a non-destructive method that provides information about the structure of materials by tapping the samples with a projectile and detecting the resulting acoustic signal with a microphone. IET measurements were performed on all samples, and Young's modulus was calculated (RFDA software, IMCE, System 23) by the following equation for cylindrical specimens:

$E=1.6067 \frac{L^{3}}{D^{4}} m f^{2} C$,

where $L$ is the length, $D$ is the diameter and $m$ is the mass of the specimen; $f$ is the measured flexural vibration frequency, and $C$ is the shape-correction factor, which is close to unity for sufficiently long specimens $(L / D>10)$.

Impact test measurements were performed on unnotched, cylindrical specimens to evaluate the differences in dynamic toughness behaviour between the pure and the copper-reinforced alumina samples. The setup was based on the lzod test for polymers. The test simulates an impact event and determines the dynamic toughness of a material under high loading rates $[44,71]$. It comprised a swinging pendulum (hammer) that was released from a fixed position in order to strike through the specimen which had been clamped at one side in the test fixture. The kinetic energy of the pendulum at that point equals the impact fracture energy required to (1) initiate and (2) complete the fracture. The impact strength (in $\mathrm{kJ} \mathrm{m}^{-2}$ ) was estimated by dividing the energy by the cross-sectional area of the cylindrical specimen [41]. As the method has been designed for polymeric materials, it may not give accurate absolute values for the toughness of ceramics without proper calibration. However, relative values obtained for samples with similar sizes but different material are quite accurate.

Vickers microhardness measurements were performed on the polished cross-section of the samples with the use of a microhardness tester (FM-700, Future-Tech). A pyramid shaped diamond indenter with square base and $130^{\circ}$ angle was used under a $9.81 \mathrm{~N}$ load and $10 \mathrm{~s}$ dwell time. The indent was measured in the microscope. A total of 15 indentation readings were taken on different locations in the matrix along the diameter of the samples, avoiding the positions of the copper particles and an average value was calculated for the bulk hardness of each composition. The distances between two indentations and between the first indentation and the specimen edge were greater than 
three times the indentation size to avoid distortion of the results [5].

\section{Results and discussion}

\subsection{Phase and density study}

The X-ray diffraction patterns of the sintered $\mathrm{Cu} / \mathrm{Al}_{2} \mathrm{O}_{3}$ samples showed no reflections other than those of copper and alumina phases (Fig. 2). All corresponding peaks that were observed in the spectra were indexed with the database according to [22].

All sintered specimens that contained a non-zero amount of copper were found to show a core-skin structure. A copper-depleted (and almost white) alumina-rich surface and a red copper-rich core could be initially discerned macroscopically due to colour variation. A typical image of this structure is shown in Fig. 3. The skin had virtually zero Cu content, while the core consisted of a dispersion of copper particles. The thickness of the skin, $d_{s}$, was less than $100 \mu \mathrm{m}$ and varied slightly with composition (Table 1).

This structure seems to be a real feature of metal-alumina composites in which the metal is molten at the sintering temperature, and not an artifact of the method used for the fabrication of the samples. Since $\mathrm{Cu}$ is in the melt state during sintering it can be argued that some copper evaporated during the process. Similar observations on the formation of a core-skin structure have been reported for Ag/Alumina composites [19, 23, 24], also assigned to evaporation of molten silver [78].

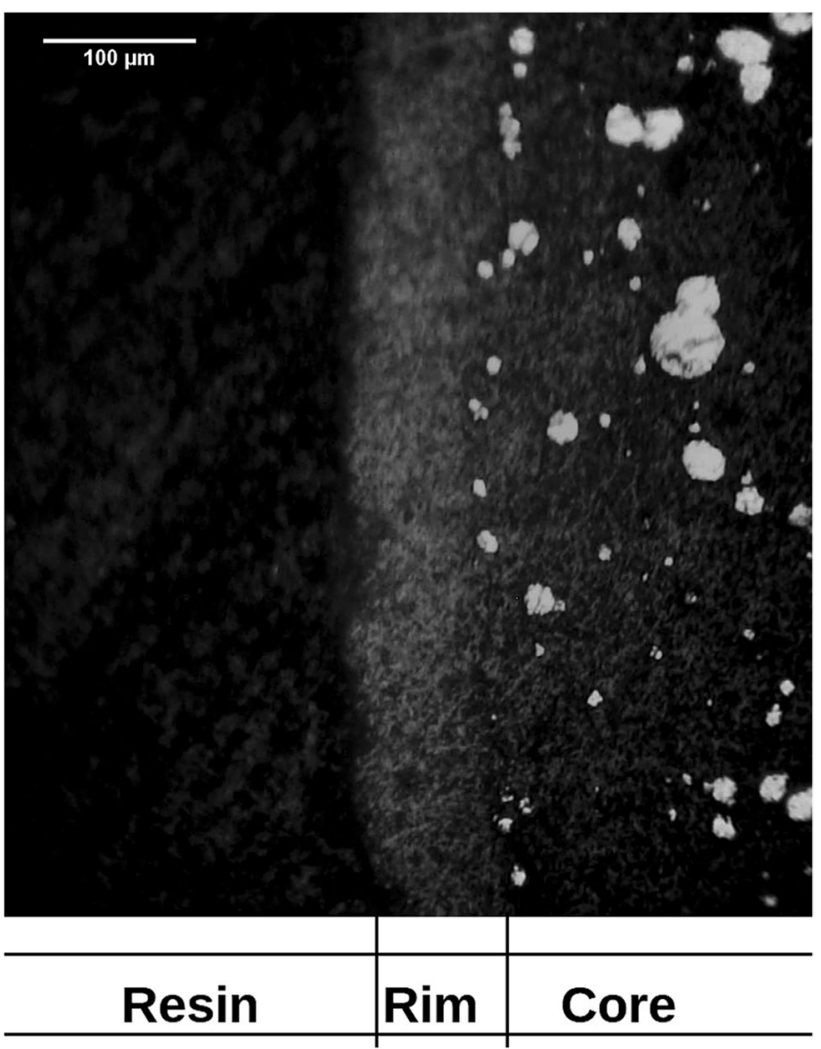

Fig. 3 Optical micrograph of a sintered $\mathrm{Cu}-\mathrm{Al}_{2} \mathrm{O}_{3}$ specimen embedded in a resin and showing a copper-depleted surface (skin) and a copper-rich core

In this work, however, the copper-free skin of the samples can only partially be attributed to copper evaporation. The weight loss that occurred for each sample after
Fig. 2 X-ray diffraction pattern of copper-reinforced alumina after sintering. The solid circles and open squares represent $\mathrm{Cu}$ and $\mathrm{Al}_{2} \mathrm{O}_{3}$, respectively

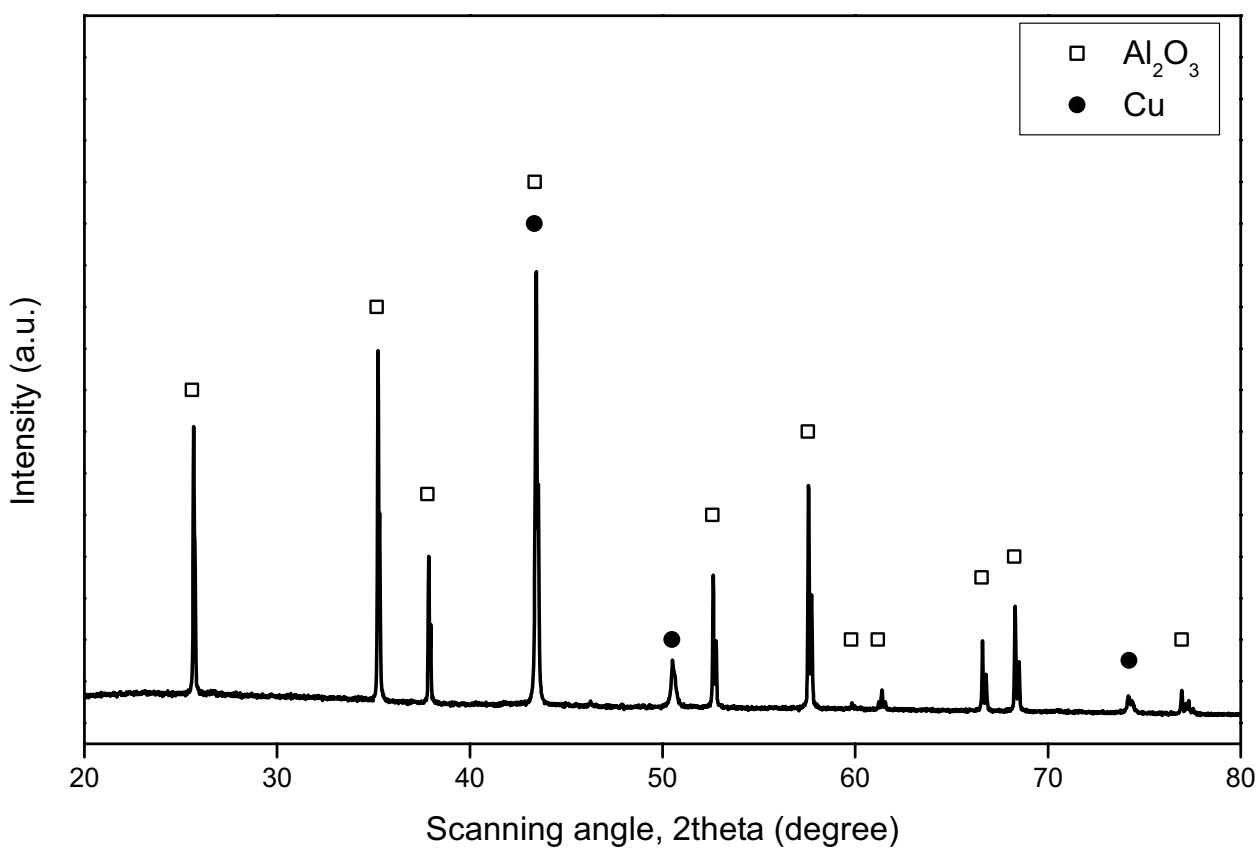


Table 1 Structural characteristics of alumina and copper-alumina composites

\begin{tabular}{lllllll}
\hline $\mathrm{Cu}(\%)$ & $\bar{\rho}_{r}(\%)$ & $\bar{\rho}(\%)$ & $\phi_{o}(\%)$ & $\phi_{c}(\%)$ & $\bar{d}(\mu \mathrm{m})$ & $d_{s}(\mu \mathrm{m})$ \\
\hline 0 & $59.7 \pm 1.9$ & $97.4 \pm 0.1$ & 0.4 & 2.2 & - & - \\
1 & $54.0 \pm 0.6$ & $96.4 \pm 1.9$ & 0.5 & 3.1 & $11.9 \pm 9.2$ & 95 \\
3 & $53.5 \pm 1.2$ & $94.9 \pm 0.5$ & 0.8 & 4.3 & $11.5 \pm 8.4$ & 78 \\
5 & $53.6 \pm 1.4$ & $94.6 \pm 0.3$ & 1.2 & 4.2 & $11.7 \pm 8.2$ & 79 \\
8 & $55.3 \pm 0.8$ & $93.8 \pm 0.2$ & 1.4 & 4.7 & $12.2 \pm 8.8$ & 67 \\
10 & $54.7 \pm 1.1$ & $91.1 \pm 0.4$ & 3.9 & 5.0 & $12.5 \pm 8.7$ & 69 \\
\hline
\end{tabular}

The columns are: volume fraction, $\mathrm{Cu}(\%)$; relative green density, $\bar{\rho}_{r}(\%)$; relative sintered density, $\bar{\rho}(\%)$; open porosity, $\phi_{o}(\%)$; closed porosity, $\phi_{c}(\%)$; mean particle size in core, $\bar{d}(\mu \mathrm{m})$; skin thickness, $d_{s}(\mu \mathrm{m})$ sintering was minimal and in the order of $0.5 \%$ for most compositions. This suggests that the core-skin structure may have been formed in the green parts during the slip-casting process, while water was being absorbed by the gypsum moulds. It seems, thus, that the escaping liquid water might have dragged some particles with it. The $\mathrm{Al}_{2} \mathrm{O}_{3}$ particles were smaller and lighter than the $\mathrm{Cu}$ particles. It is possible, then, that the former were carried away faster than the latter. Thus, the copper particles in the slurry near the mould cavity wall had a better chance to be dragged away than the particles farther inside the mould. This could explain the formation of the copper-free skin but may lead to a higher porosity in the skin than in the core. The last point has to be further investigated.

The relative green, $\bar{\rho}_{r}$, and sintered, $\bar{\rho}$, densities of the whole samples (skin and core) are shown in Table 1. Pure alumina has a $\bar{\rho}_{r}$ of around $60 \%$. The values of $\bar{\rho}_{r}$ of the composites fluctuate around $54-55 \%$, which seem to be sufficient to produce high enough sintered densities [69].

Pure alumina has a sintered density of more than $97 \%$, while addition of copper produces composites with slightly reduced $\bar{\rho}$. This may be due to two mechanisms. The densification of the composites may be hindered by the presence of the copper particles due to the poor wetting of the $\mathrm{Al}_{2} \mathrm{O}_{3}$ matrix by the copper: the contact angle formed by liquid copper and polycrystalline alumina remains well above $90^{\circ}$ for the entire sintering process [48]. Further, the large difference in volume change during heating/cooling of expansion and contraction between the two phases results in different shrinkage rates and does not favour the formation of a mechanical bonding between the particles and the matrix [80]. Thus, voids may be formed in the matrix and account for the decrease of the relative density at higher copper loading.

Nevertheless, the final density of all samples is rather high, especially when compared with similar composites in the literature that have been prepared via pressureless sintering. For example, [1] prepared $\mathrm{Cu} / \mathrm{Al}_{2} \mathrm{O}_{3}$ composites using the same alumina powder $\left(\mathrm{CT} 3000 \mathrm{SG}_{2} \mathrm{O}_{3}\right)$ and a much finer copper powder (size $\sim 2 \mu \mathrm{m}$ ). The powders were mixed and uniaxially pressed at 70MPa, followed by pressureless sintering at $1600{ }^{\circ} \mathrm{C}$ for $2 \mathrm{~h}$ and reached a maximum of $91.2 \%$ for $\bar{\rho}$ for samples containing 5 vol\% $\mathrm{Cu}$. This corroborates to the suitability of the slip-casting processing route for the fabrication of copper/alumina composites as it can produce more dense green parts than conventional dry pressing, despite the pressureless sintering which tends to hinder full densification.

Dry pressing is a simple method for the fabrication of ceramics and ceramic-based composites. However it achieves rather low and/or non-uniform green densities, which result in low sintered densities and/or defects. The initial powder may be agglomerated and may remain so after pressing, resulting in remaining pores $[40,58]$. On the other hand, the use of the slip-casting processing route yields samples with reasonably high green densities and a homogeneous green microstructure because of the good particle packing of the powders. The latter seems to be induced by the high capillary forces of the escaping water into the gypsum mould.

\subsection{Microstructure}

The microstructure of the core of the samples is shown in Fig. 4. The copper particles can be discerned as bright spots in the dark background which represents the alumina matrix. A homogeneous spatial distribution can be seen throughout the core in all composites. The size of copper particles did not vary significantly with composition, although a few agglomerated regions were observed for higher copper loading.

Table 1 lists the number-weighted mean particle size, $\bar{d}$, of the inclusions in the sintered samples. This size is comparable to the size of the Cu raw powder [38].

The SEM image of Fig. 5 shows the interface between a spherical copper particle and the alumina matrix. It can be seen that there is some empty space between the surface of the copper inclusion and the grains of the alumina matrix. This apparently comes from the larger contraction of the copper particle during cooling from the sintering temperature. While the density of solid copper is $8.941 \mathrm{~g} \mathrm{~cm}^{-3}$, the density of liquid copper at 


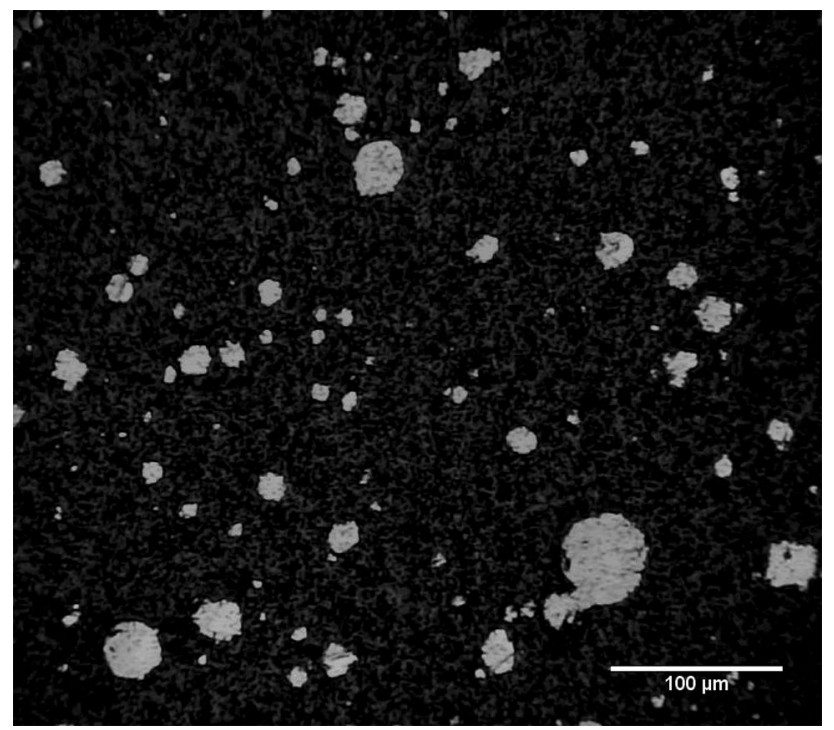

Fig. 4 Optical micrograph from the polished cross section of the 8 vol\% $\mathrm{Cu} / \mathrm{Al}_{2} \mathrm{O}_{3}$ composite material

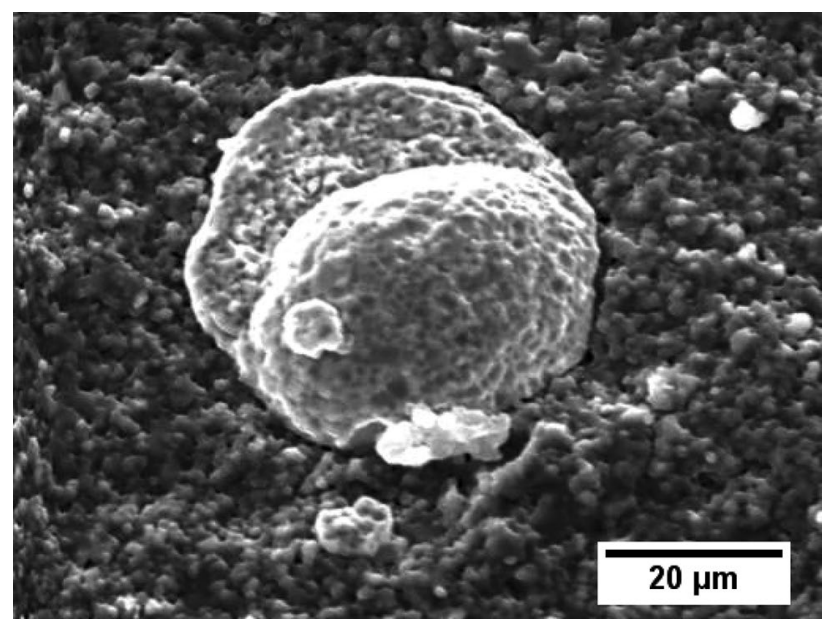

Fig. 5 Scanning electron micrograph showing a partially deformed spherical copper particle between alumina grains on a fracture surface

its melting point $\left(1083^{\circ} \mathrm{C}\right)$ is $7.992 \mathrm{~g} \mathrm{~cm}^{-3}$ and near the sintering temperature $\left(1527^{\circ} \mathrm{C}\right)$ it is $7.636 \mathrm{~g} \mathrm{~cm}^{-3}$ [13]. As a result, a droplet of liquid copper shrinks around $12 \%$ when cooled from the sintering temperature to its solid state. Therefore, the difference in shrinkage between the surrounding alumina and a liquid copper droplet of $40 \mu \mathrm{m}$ diameter would be around $1.5 \mu \mathrm{m}$. Indeed Fig. 5 suggests an interfacial void of the same order of magnitude for such a particle.

\subsection{Mechanical properties}

\subsubsection{Stiffness}

The measured Young's modulus data, $E$, are listed in Table 2 . It is evident that the copper/alumina composites exhibit lower values than those of the pure alumina. Naturally this is due to both the presence of the softer metallic inclusions and the residual porosity of the matrix. The measured values are comparable with results published for hot-pressed $\mathrm{Cu}$ / $\mathrm{Al}_{2} \mathrm{O}_{3}$ composites with similar $\mathrm{Cu}$ vol\% but lower amounts $(<1 \%)$ of residual porosity [79].

If no synergistic or antagonistic interactions between the components are present, the series and the parallel mixing models are expected to give the upper $\left(E^{+}\right)$and lower $\left(E^{-}\right)$ bounds of the values for the modulus of the composite [34-36]:

$E^{+}=E_{f} V_{f}+E_{m}\left(1-V_{f}\right)$,

$E^{-}=\frac{E_{m} E_{f}}{E_{m} V_{f}+E_{f}\left(1-V_{f}\right)}$,

where $V_{f}$ is the volume fraction of the reinforcement and $E_{f}, E_{m}$ are the elasticity moduli of the reinforcement and the matrix respectively.

Ceramic materials and ceramic-based composites have varying degrees of porosity because they cannot be completely densified via conventional sintering processes. Thus, their elastic moduli decrease in the presence of porosity, as voids have almost no stiffness. Models that provide tentative predictions of the effect of porosity on $E$ include those of Voigt and Hashin-Shtrikman [33, 55], and the power-law relations of Coble-Kingery and Gibson-Ashby [20, 31, 51]. An exponential formulation proposed by [52] was found, however, to provide a better fit of the data as it predicts a steeper decrease of the experimental curves, $E(\phi)$ :

$E_{p}=E_{0} \exp \left(\frac{-2 \phi}{1-\phi}\right)$

Table 2 Young's modulus $(E)$, Vickers hardness (HV) and unnotched Izod impact strength $\left(a_{I U}\right)$ of the copper/alumina composites

\begin{tabular}{llll}
\hline Cu (vol\%) & $E(\mathrm{GPa})$ & $\mathrm{HV}(\mathrm{GPa})$ & $a_{I U}\left(\mathrm{~kJ} \mathrm{~m}^{-2}\right)$ \\
\hline 0 & 374.4 & $25.9 \pm 2.6$ & $4.9 \pm 0.8$ \\
1 & 353.9 & $23.5 \pm 4.5$ & $7.6 \pm 1.8$ \\
3 & 332.7 & $21.4 \pm 4.6$ & $7.1 \pm 1.4$ \\
5 & 334.8 & $19.4 \pm 3.0$ & $2.9 \pm 0.4$ \\
8 & 323.7 & $20.6 \pm 2.1$ & $2.3 \pm 0.2$ \\
10 & 293.1 & $20.3 \pm 4.4$ & $3.1 \pm 1.1$ \\
\hline
\end{tabular}




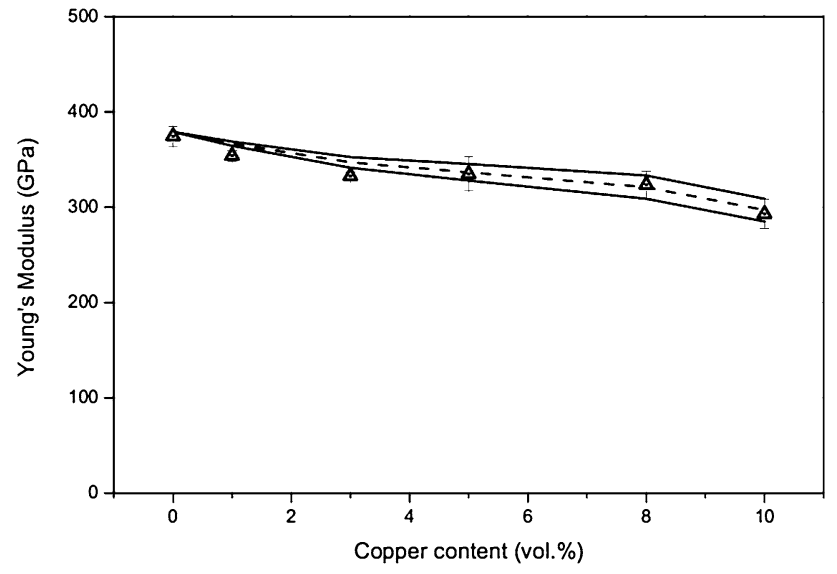

Fig. 6 Young's modulus of the copper-alumina composites as a function of copper content. The lines indicate the porosity-corrected (by Eq. 5) upper and lower bounds (Eqs. 3-4; solid lines) and arithmetic mean (dashed line)

Here $E_{p}$ is the modulus of the porous material, $E_{0}$ is the modulus of the dense (pore-free) material, and $\phi$ is the (total) porosity.

Figure 6 depicts Young's modulus of the composites as a function of copper content. It can be observed that the experimental data (symbols) concur with the theoretical predictions (lines) of $E_{p}$. The value $E_{0}=400 \mathrm{GPa}$ has been taken from the literature for the fully-dense (non-porous) polycrystalline alumina [54] and Eq. 5 was used to correct the modulus of the matrix for the porosity. It is evident that the data fall within the limits of Eqs. 3 and 4, i.e., the simple mixing rule can adequately describe the elastic behaviour of the composites.

The reduction in stiffness is anticipated given the dispersion of less stiff metallic particles in a very stiff ceramic-matrix. Theoretically, the values should remain within the upper and lower bounds of the mixing rules $[11,12,43,57,74]$. On the other hand, any deviations of measured data from the lower-bound values could be the result of (frequent) elastic or thermal mismatch between the metal and ceramic phases which may create localised residual stresses in the matrix $[18,65,66$, 75]. In addition, a poor metal/alumina interfacial bonding may also justify this divergence [2] because the elastic modulus is a macroscopic parameter closely related to atomic bonding. In the present study the good agreement between the experimental values and the simple rules of mixing corroborates to the presence of an interface that can support sufficiently the load transfer from the matrix to the reinforcement, i.e., to better cohesion between the solid copper inclusions and the alumina matrix.

\subsubsection{Toughness}

Table 2 and Fig. 7 show the results derived from the impact test measurements that were performed on the alumina and the copper-alumina specimens. As it can be seen from the graph, the impact resistance of the copper-alumina composites varied strongly with composition. The composites with 1 and 3 vol\% copper content exhibited an impact strength that was around 1.5 times higher than that of the pure alumina, while the impact strength of the composites with higher copper loading was lower. Unlike the stiffness and hardness of the composites that conform to a linear trend, the fracture resistance of the composites exhibits non-linear dependence on copper loading. This behaviour is in accordance with relevant literature data for metal-particle reinforced alumina-matrix composites $[25,66,77]$ and urges us to forward the discussion on two levels: (1) the factors that contribute to the toughness enhancement, and (2) the factors that bring about the reduction of toughness.

The increased fracture energy and, therefore, augmented impact resistance of the $\mathrm{Cu}$ /alumina samples with 1 and 3 vol\% is directly related to the dispersion of the copper inclusions $[62,68]$. This enhancement may be attributed to the activation of a number of toughening mechanisms such as the deflection or the bridging of the cracks by the particles, or the debonding along the particle/matrix interface. These mechanisms might act independently or in conjunction $[1,72,79]$.

The examination of the fracture surfaces reveals the presence of copper particles in different states: (1) whole spherical particles, half stuck in the matrix (presumably detached during fracture from the other half of the specimen); (2) missing particles that have left a hemispherical hole when they were detached; (3) broken particles;

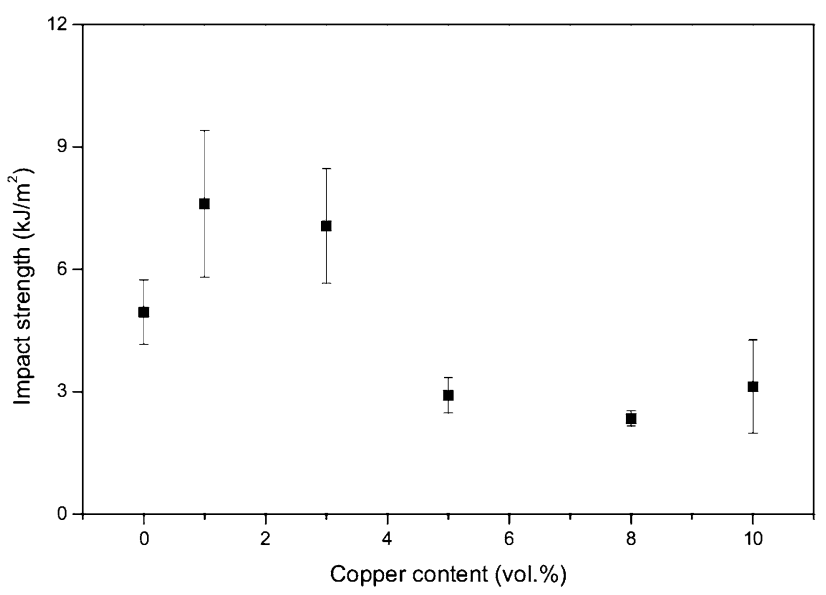

Fig. 7 Impact strength as a function of copper loading for the sintered copper-alumina composites 
(4) broken or whole particles that have been plastically deformed (Fig. 8).

The latter point (i.e. the intercepted and broken ductile particle theory) was proposed by [3]. The presence of stretched Cu particles is consistent with the crack bridging mechanism and verifies its activation in the particular copper/alumina composites. Nonetheless, a fraction of the second-phase inclusions has remained relatively undeformed by the fracture process and did not interact strongly with the propagating crack [73].

The presence of deformed and broken particles on the fracture surfaces indicate that the interfacial bonding between the copper inclusions and the alumina matrix is not as poor as their interfacial tension would suggest. This, along with the bridging of the crack by the particles, seems to have contributed to the toughening of the composites. The available space around the spherical Cu inclusions suggests some degree of freedom for the ductile particles to stretch and deform upon their interaction with the propagating crack. On the other hand, these voids could trigger a mechanism of toughening via debonding [42].

The ideal bonding between the dispersed particles and the matrix material has been extensively studied. It is thought that, in order to utilise the ductility and fully exploit the toughening potential of the inclusions, the bonding should preferentially be neither very weak nor very strong. The former has negligible contribution to toughness, and the latter would impose constraints on the particles [39]. It seems, therefore, that the enhancement of the toughness in our case is due to the proper value of the interfacial strength of the copper/alumina system.
Further, the fact that the elastic modulus of the metallic inclusion was lower than that of the ceramic matrix material facilitated the attraction of the propagating crack by the particles (rather than overpassing them) [7].

Another factor of great significance for the toughness of the composites is the porosity. For low copper volume fractions, the open porosity of the composites was low, but it increased significantly in the composites with higher $\mathrm{Cu}$ loading. Table 1 shows that the samples with pure $\mathrm{Al}_{2} \mathrm{O}_{3}$ or with low Cu content ( 1 and 3 vol\%) had pores that were essentially closed. The open porosity was negligible at $\phi_{0}<1 \%$. The ratio of open over the total porosity remained unchanged (around 0.15 ) for the composites with 0, 1 and 3 vol\% Cu. This implies that the initiation of the crack in the composites required the same amount of energy as that in alumina. Therefore, the subsequent enhancement of the toughness should be attributed to the propagation of the crack and its interaction with the $\mathrm{Cu}$ inclusions that are dispersed in the bulk (core) of the material.

On the other hand, the open porosity increases in the composites with more than 5 vol\% Cu, even though the closed porosity remains at around $4-5 \%$. The ratio of open over total porosity becomes as high as 0.44 for the composite with 10 vol\% Cu. This suggests that the elevated value of the open porosity has expedited the initiation of the crack and it has partly cancelled out the advantageous effect of the dispersed second-phase inclusions. It should be reminded here that the specimens were unnotched, and the test method determined the total absorbed energy as the sum of the energies for crack initiation and for crack
Fig. 8 SEM micrographs of the fracture surfaces of sintered $\mathrm{Cu} / \mathrm{Al}_{2} \mathrm{O}_{3}$ composites a

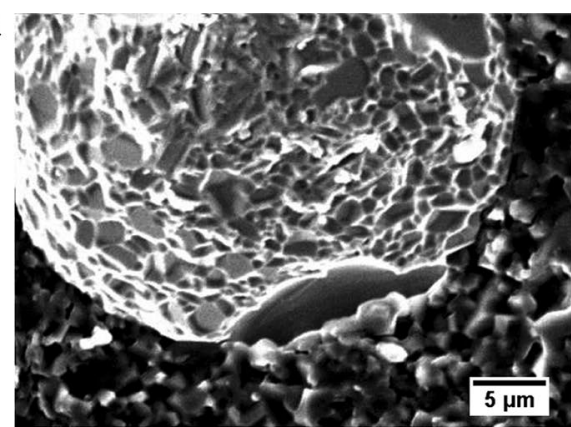

C

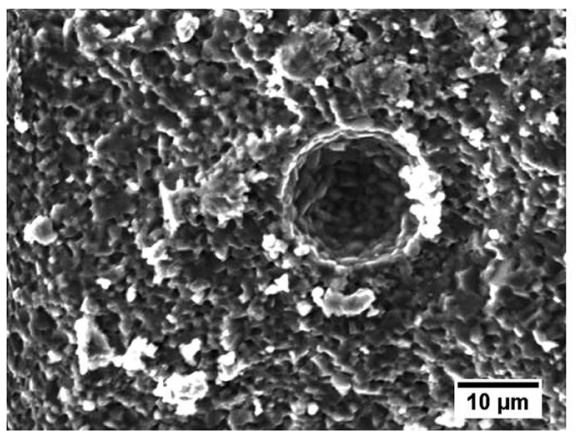

b
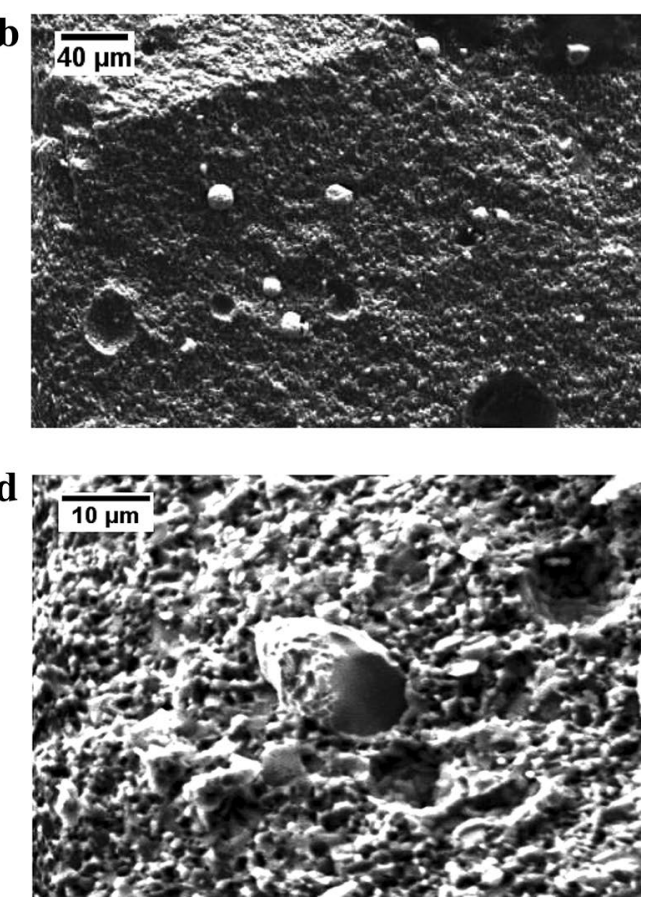

SN Applied Sciences 
propagation [56]. Therefore, surface properties (i.e. open porosity) do not stimulate the activation of a toughening mechanism.

It can be concluded that the impact response of the specimens is the result of three parameters: (1) the plasticity of the ductile metal and its positive contribution to the toughness (for low copper loading), (2) the volume fraction of $\mathrm{Cu}$ and the possible formation of agglomerated regions locally that might deteriorate the toughness, and (3) the ratio of open vs total porosity (i.e. surface characteristics of the samples). Although, in theory, the higher the particle loading the higher the toughening effect, provided that we have a highly ductile inclusion and a notable possibility for crack bridging to occur, it appears that there is a threshold (critical metal volume fraction) beyond which the contribution of the particles is not beneficial, but rather diminishes the mechanical behavior of the composites.

\subsubsection{Vickers hardness}

The Vickers hardness experimental data are shown in Table 2 and Fig. 9. These correspond to average values calculated from a number of indentations that were performed on the matrix at different positions in the core of the polished crosssection of each sample, avoiding the copper particles. The solid line in Fig. 9 represents a linear relation between the hardness of alumina and copper. Moreover, as the hardness of ceramics is also affected by the presence of void spaces throughout the matrix material, an empirical exponential equation can be applied to account for this residual porosity and predict the hardness of porous ceramics, in the form of [59]:

$H V=V_{f} H V_{C u}+\left(1-V_{f}\right) H V_{\mathrm{Al}_{2} \mathrm{O}_{3}} \exp (-b \phi)$,

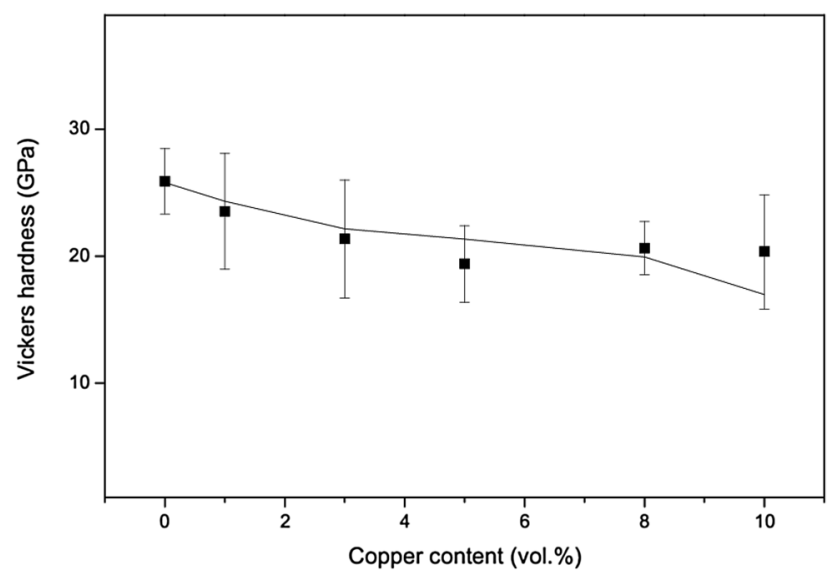

Fig. 9 Vickers hardness experimental data (squares) compared with the estimation (solid line) by the rule of mixing after the corresponding porosity-correction (Eq. 6) where $\mathrm{HV}_{\mathrm{Cu}}$ and $\mathrm{HV}_{\mathrm{Al}_{2} \mathrm{O}_{3}}$ are the hardness values of copper and (the fully-dense) alumina taken from the literature: $0.37 \mathrm{GPa}$ for $\mathrm{Cu}$ and $29.4 \mathrm{GPa}$ for $\mathrm{Al}_{2} \mathrm{O}_{3}$ [15]; $\phi$ is the total porosity; and $b$ is a parameter that varies between 1 and 9 [60] and was assigned here the value of 5 to fit the experimental data of the pure alumina samples.

The hardness of the composites remains reasonably high for all compositions and decreases slightly when copper particles are added, from $25 \mathrm{GPa}$ (for pure alumina) to $20 \mathrm{GPa}$ (Table 2). This decrease is evidently attributed to the dispersion of the softer particles in the ceramic matrix. Yet, the presence of pores in the matrix material has also contributed to this reduction [73].

Even though the microhardness measurement was conducted in alumina regions, avoiding the dispersed metallic particles, the result is affected by the overall structure of the composite. The data refer to the local hardness of alumina and show the influence of the interaction of the matrix with both the softer second-phase inclusions and the residual pores on the hardness of the matrix. Further, the measured hardness values are influenced by the whole microstructure of the specimen which includes "hidden" particles and voids under the examined surface. As there is no significant agglomeration of particles at higher volume fractions, the hardness of the matrix material decreases with the addition of more particles because the distance between them decreases and their effect on alumina increases. In total, the data are in good agreement with the estimation of the rule of mixing after the corresponding porosity-correction.

\section{Conclusions}

The present report shows that the slip-casting technique followed by hydrogen sintering of the green parts can be employed as a processing route for the successful synthesis of copper-alumina composites with enhanced impact resistance behaviour, whilst maintaining a hard composite microstructure with limited loss of stiffness. The optimum combination of properties seems to be obtained at low (< 5 vol\%) copper particle content.

A skin-core structure was formed in all the composite samples that were prepared. The structure consisted of a copper-depleted alumina surface layer and uniformly distributed copper particles in the core. The mechanical properties of the ceramic were affected by the presence of the softer particles and the skin-core structure. The elastic moduli were reduced only by the contribution of the softer component, indicating the absence of antagonistic effects of the constituents. This was verified by the values of the 
microhardness of the matrix, which remained relatively high.

The enhancement of toughness at low $\mathrm{Cu}$ content seems to be due to the proper degree of bonding between the two phases in the core. Post-mortem analysis of the fracture surfaces elucidated the mechanisms of the enhancement of toughness for these composites. It confirmed the bridging of the advancing crack by the ductile copper inclusions and revealed the pull-out of the particles from the matrix material that may be accountable for the reduction in impact strength observed for the composites with higher $\mathrm{Cu}$ content. The decrease in toughness is also attributed to the brittle alumina-rich skin of the samples, which cannot compensate for the effectiveness of the core-dispersed particles; and the open porosity, which increases with the volume fraction of the particles and acts as surface flaw facilitating, thus, a faster crack initiation.

Acknowledgements M.S. would like to thank Dr. E. Gregorová, UCT Prague, for the laser diffraction analysis, Dr. J. Zýka, UJP PRAHA a.s., for the sintering equipment and Dr. A. Stratakis, TUC, for the XRD data. Sandvik Osprey Ltd is acknowledged for the provision of the copper powder

Funding The study of M.S. and A.G. (TUC) was partly funded by the Research Program $\Theta A \Lambda H \Sigma$ (European Social Fund and Greek National Funds).

\section{Compliance with ethical standards}

Conflict of interest On behalf of all authors, the corresponding author states that there is no conflict of interest.

\section{References}

1. Aldrich D, Edirisinghe $M(1998)$ Addition of copper particles to an alumina matrix. J Mater Sci Lett 17(12):965-967

2. Aldridge M, Yeomans J (1999) The thermal shock behaviour of ductile particle toughened alumina composites. J Eur Ceram Soc 19(9):1769-1775

3. Ashby M, Blunt F, Bannister M (1989) Flow characteristics of highly constrained metal wires. Acta Metall 37(7):1847-1857

4. ASTM-E-1876-15 (2015) Standard test method for dynamic young's modulus, shear modulus, and Poisson's ratio by impulse excitation of vibration. Technical report, ASTM International, West Conshohocken, PA

5. ASTM-E-384-17 (2017) Standard test method for microindentation hardness of materials. Technical report, ASTM International, West Conshohocken, PA

6. Azar M, Palmero P, Lombardi M, Garnier V, Montanaro L, Fantozzi G, Chevalier J (2008) Effect of initial particle packing on the sintering of nanostructured transition alumina. J Eur Ceram Soc 28(6):1121-1128

7. Bao G, Chung-Yuen H (1990) Effects of interface debonding on the toughness of ductile-particle reinforced ceramics. Int J Solids Struct 26(5):631-642
8. Barsoum M, Barsoum M (2002) Fundamentals of ceramics. Series in material science and engineering. Taylor \& Francis, London

9. Basu B, Balani K (2011) Advanced structural ceramics. Wiley, Hoboken

10. Becher $P$ (1991) Microstructural design of toughened ceramics. J Am Ceram Soc 74(2):255-269

11. Breval E, Deng Z, Chiou S, Pantano CG (1992) Sol-gel prepared Ni-alumina composite materials. J Mater Sci 27(6):1464-1468

12. Broniszewski K, Wozniak J, Czechowski K, Jaworska L, Olszyna A (2013) $\mathrm{Al}_{2} \mathrm{O}_{3}-$ Mo cutting tools for machining hardened stainless steel. Wear 303(1):87-91

13. Cahill J, Kirshenbaum A (1962) The density of liquid copper from its melting point $\left(1356^{\circ} \mathrm{K}\right)$ to $2500^{\circ} \mathrm{K}$ and an estimate of its critical constants. J Phys Chem 66:1080-1082

14. Callister W, Rethwisch D (2009) Materials science and engineering: an introduction, 8th edn. Wiley, Hoboken

15. Cardarelli F (2008) Materials handbook: a concise desktop reference. Springer, London

16. Carter C, Norton M (2007) Ceramic materials: science and engineering. Springer ebook collection/chemistry and materials science 2005-2008. Springer, New York

17. Chawla K (2013) Composite materials: science and engineering. Materials research and engineering. Springer, New York

18. Chen R, Chiu Y, Tuan W (2000) Toughening alumina with both nickel and zirconia inclusions. J Eur Ceram Soc 20(12):1901-1906

19. Chou W, Tuan W (1995) Toughening and strengthening of alumina with silver inclusions. J Eur Ceram Soc 15(4):291-295

20. Coble R, Kingery W (1956) Effect of porosity on physical properties of sintered alumina. J Am Ceram Soc 39(11):377-385

21. DIN EN 993-1 (1995) Methods of test for dense shaped refractory products. Determination of bulk density, apparent porosity and true porosity. Technical report, Standard by DIN-adopted European Standard

22. Downs R, Hall-Wallace M (2003) The American Mineralogist Crystal Structure Database. Am Mineral 88(1):247-250

23. Dutta A, Chattopadhyaya A, Ray K (2006) Progressive flank wear and machining performance of silver toughened alumina cutting tool inserts. Wear 261(7):885-895

24. Dutta A, Narasaiah N, Chattopadhyaya A, Ray K (2001) The load dependence of hardness in alumina-silver composites. Ceram Int 27(4):407-413

25. Díaz L, Valdés A, Díaz C, Espino A, Torrecillas R (2003) Alumina/ molybdenum nanocomposites obtained in organic media. J Eur Ceram Soc 23(15):2829-2834

26. Evans A (1990) Perspective on the development of high-toughness ceramics. J Am Ceram Soc 73(2):187-206

27. Evans A, McMeeking R (1986) On the toughening of ceramics by strong reinforcements. Acta Metall 34(12):2435-2441

28. Faber K, Evans A (1983a) Crack deflection processes-I. Theory. Acta Metall 31(4):565-576

29. Faber K, Evans A (1983b) Crack deflection processes-II. Experiment. Acta Metall 31(4):577-584

30. Gao F, Wang T (1990) Apparent fracture energy of brittle materials by branching of crack and microcrack. J Mater Sci Lett 9(12):1409-1411

31. Gibson JL, Ashby FM (1982) The mechanics of three-dimensional cellular materials. Proc R Soc Lond Ser A 382(1782):43-59

32. Green D (1998) An introduction to the mechanical properties of ceramics. Cambridge solid state science series. Cambridge University Press, Cambridge

33. Hashin Z, Shtrikman S (1963) A variational approach to the theory of the elastic behaviour of multiphase materials. J Mech Phys Solids 11(2):127-140

34. Hill R (1952) The elastic behaviour of a crystalline aggregate. Proc Phys Soc Lond Sect A 65(5):349 
35. Hill R (1963) Elastic properties of reinforced solids: some theoretical principles. J Mech Phys Solids 11(5):357-372

36. Hirsch T (1962) Modulus of elasticity of concrete affected by elastic moduli of cement paste matrix and aggregate. $\mathrm{ACl} J$ Proc 59(3):427-452

37. Ighodaro O, Okoli O (2008) Fracture toughness enhancement for alumina systems: a review. Int J Appl Ceram Technol 5(3):313-323

38. Konopka K, Oziębło A (2001) Microstructure and the fracture toughness of the $\mathrm{Al}_{2} \mathrm{O}_{3}-\mathrm{Fe}$ composites. Mater Charact 46(2):125-129

39. Krstic V (1983) On the fracture of brittle-matrix/ductile-particle composites. Philos Mag A 48(5):695-708

40. Lange FF (1989) Powder processing science and technology for increased reliability. J Am Ceram Soc 72(1):3-15

41. Low I (2018) Advances in ceramic matrix composites. Woodhead Publishing series in composites science and engineering. Elsevier, Amsterdam

42. Lu J, Gao L, Sun J, Gui L, Guo J (2000) Effect of nickel content on the sintering behavior, mechanical and dielectric properties of $\mathrm{Al}_{2} \mathrm{O}_{3} / \mathrm{Ni}$ composites from coated powders. J Mater Sci Eng A 293(1):223-228

43. Lucchini E, Casto SL, Sbaizero O (2003) The performance of molybdenum toughened alumina cutting tools in turning a particulate metal matrix composite. J Mater Sci Eng A 357(1):369-375

44. Mouritz A (2012) Introduction to aerospace materials. Woodhead Publishing in materials. Elsevier, Amsterdam

45. Moya J, Lopez-Esteban S, Pecharromàn C (2007) The challenge of ceramic/metal microcomposites and nanocomposites. Prog Mater Sci 52(7):1017-1090

46. Munro M (1997) Evaluated material properties for a sintered alpha-alumina. J Am Ceram Soc 80(8):1919-1928

47. Nawa M, Sekino T, Niihara K (1994) Fabrication and mechanical behaviour of $\mathrm{Al}_{2} \mathrm{O}_{3} / \mathrm{Mo}$ nanocomposites. J Mater Sci 29(12):3185-3192

48. Nikolopoulos $P$, Agathopoulos $S$ (1992) Interfacial phenomena in $\mathrm{Al}_{2} \mathrm{O}_{3}$-liquid metal and $\mathrm{Al}_{2} \mathrm{O}_{3}$-liquid alloy systems. J Eur Ceram Soc 10(6):415-424

49. Oh S-T, Sekino T, Niihara K (1998) Fabrication and mechanical properties of 5 vol\% copper dispersed alumina nanocomposite. J Eur Ceram Soc 18(1):31-37

50. Oziębło A, Konopka K, Bobryk E, Szafran M, Kurzydlowski K (2004) $\mathrm{Al}_{2} \mathrm{O}_{3}-\mathrm{Fe}$ functionally graded materials fabricated under magnetic field. Solid State Phenom 101:143-146

51. Pabst W, Gregorová E (2003) Note on the so-called CobleKingery formula for the effective tensile modulus of porous ceramics. J Mater Sci Lett 22(13):959-962

52. Pabst W, Gregorová E (2004) Mooney-type relation for the porosity dependence of the effective tensile modulus of ceramics. J Mater Sci 39(9):3213-3215

53. Pabst W, Gregorová E, Sedlářová I, Černý M (2011) Preparation and characterization of porous alumina-zirconia composite ceramics. J Eur Ceram Soc 31(14):2721-2731

54. Pabst W, Tichá G, Gregorová E (2004) Effective elastic properties of alumina-zirconia composite ceramics-part 3. Calculation of elastic moduli of polycrystalline alumina and zirconia from monocrystal data. Ceram Silik 48(2):41-48

55. Paul B (1960) Prediction of elastic constants of multiphase materials. Trans Metall Soc AIME 218:36-41

56. Pelleg J (2014) Mechanical properties of ceramics. Solid mechanics and its applications. Springer, Berlin

57. Portu GD, Guicciardi S, Melandri C, Monteverde F (2007) Wear behaviour of $\mathrm{Al}_{2} \mathrm{O}_{3}-\mathrm{Mo}$ and $\mathrm{Al}_{2} \mathrm{O}_{3}-\mathrm{Nb}$ composites. Wear 262(11):1346-1352
58. Rahaman M (2003) Ceramic Processing and Sintering. Materials Engineering. Taylor \& Francis, London

59. Rice R (1989) Relation of tensile strength-porosity effects in ceramics to porosity dependence of Young's modulus and fracture energy, porosity character and grain size. J Mater Sci Eng A 112(Supplement C):215-224

60. Rice R (1996) Grain size and porosity dependence of ceramic fracture energy and toughness at $22^{\circ} \mathrm{C}$. J Mater Sci 31(8):1969-1983

61. Rodriguez-Suarez T, Díaz L, Torrecillas R, Lopez-Esteban S, Tuan W-H, Nygren M, Moya J (2009) Alumina/tungsten nanocomposites obtained by spark plasma sintering. Compos Sci Technol 69(14):2467-2473

62. Sbaizero O, Pezzotti G, Nishida T (1998) Fracture energy and $\mathrm{R}$-curve behavior of $\mathrm{Al}_{2} \mathrm{O}_{3}$ composites. Acta Mater 46(2):681-687

63. Schneider C, Rasband W, Eliceiri K (2012) NIH Image to ImageJ: 25 years of image analysis. Nat Methods 9:671-675

64. Sekino T, Nakajima T, Niihara K (1996) Mechanical and magnetic properties of nickel dispersed alumina-based nanocomposite. Mater Lett 29(1):165-169

65. Sekino T, Niihara K (1995) Microstructural characteristics and mechanical properties for $\mathrm{Al}_{2} \mathrm{O}_{3}$ /metal nanocomposities. Nanostruct Mater 6(5):663-666

66. Sekino T, Niihara K (1997) Fabrication and mechanical properties of fine-tungsten-dispersed alumina-based composites. J Mater Sci 32(15):3943-3949

67. Sigl L, Mataga P, Dalgleish B, McMeeking R, Evans A (1988) On the toughness of brittle materials reinforced with a ductile phase. Acta Metall 36(4):945-953

68. Simpson $\mathrm{L}$, Wasylyshyn $\mathrm{A}$ (1971) Fracture energy of $\mathrm{Al}_{2} \mathrm{O}_{3}$ containing Mo fibers. J Am Ceram Soc 54(1):56-57

69. Somiya S, Aldinger F, Spriggs R, Uchino K, Koumoto K, Kaneno M (2003) Handbook of advanced ceramics: materials, applications, processing and properties. Elsevier, Amsterdam

70. Sun X, Yeomans JA (1996) Microstructure and fracture toughness of nickel particle toughened alumina matrix composites. J Mater Sci 31(4):875-880

71. Tamin M (2012) Damage and fracture of composite materials and structures. Advanced structured materials. Springer, Berlin

72. Travitzky N (1998) Microstructure and mechanical properties of alumina/copper composites fabricated by different infiltration techniques. Mater Lett 36(1):114-117

73. Tuan W, Brook R (1990) The toughening of alumina with nickel inclusions. J Eur Ceram Soc 6(1):31-37

74. Tuan W, Chen J, Yang T (2007) Minimum amount of nanosized nickel particles to enhance the strength of alumina. $J$ Eur Ceram Soc 27(16):4705-4709

75. Tuan W, Chen R (2002) Interactions between toughening mechanisms: transformation toughening versus plastic deformation. J Mater Res 17(11):2921-2928

76. Tuan W, Wu H, Chen R (1997) Effect of sintering atmosphere on the mechanical properties of $\mathrm{Ni}-\mathrm{Al}_{2} \mathrm{O}_{3}$ composites. J Eur Ceram Soc 17(5):735-741

77. Tuan $\mathrm{WH}, \mathrm{Wu} \mathrm{HH}$, Yang TJ (1995) The preparation of $\mathrm{Al}_{2} \mathrm{O}_{3} /$ $\mathrm{Ni}$ composites by a powder coating technique. J Mater Sci 30(4):855-859

78. Wang J, Ponton C, Marquis P (1993) Microstructure and mechanical properties of pressureless sintered alumina-silver composites. J Phys IV 03(C7):1769-1774

79. Wang L, Shi J-L, Lin M-T, Chen H-R, Yan D-S (2001) The thermal shock behavior of alumina-copper composite. Mater Res Bull 36(5):925-932 
80. Xia K, Langdon TG (1994) The toughening and strengthening of ceramic materials through discontinuous reinforcement. J Mater Sci 29(20):5219-5231

81. Yeomans J (2008) Ductile particle ceramic matrix compositesscientific curiosities or engineering materials? J Eur Ceram Soc 28(7):1543-1550
82. Zygmuntowicz J, Miazga A, Konopka K, Kaszuwara W (2016) Structural and mechanical properties of graded composite $\mathrm{Al}_{2} \mathrm{O}_{3} / \mathrm{Ni}$ obtained from slurry of different solid content. Procedia Struct Integr 1:305-312 